\title{
Carta do Editor
}

Abrimos o volume 11 da Gestão \& Produção com uma surpresa para você, leitor: o aumento do número de artigos publicados. Isso reflete, de certa forma, o aumento da produção intelectual da academia brasileira de Engenharia de Produção em termos de quantidade. Para nossa felicidade, a cada ano recebemos mais manuscritos, e assim está sendo possível proporcionar ao leitor mais artigos sobre Engenharia de Produção.

Apesar do aumento da quantidade dos manuscritos submetidos à publicação na Gestão \& Produção, cabe aqui algumas dicas do editor para os autores e autoras. Muitos manuscritos são recusados pelos referees por sintomaticamente apresentarem problemas como: falta de objetivo claro; muita ênfase na revisão bibliográfica e pouca na contribuição do trabalho, ou vice-versa; método de pesquisa não detalhado ou incoerente com o objetivo e/ou conclusão do manuscrito; e falta de clareza na construção do referencial teórico. Além disso, nestes anos como editor, tenho visto vários manuscritos, originados de dissertações e teses, serem rejeitados principalmente porque a atividade de copy and paste, de forma geral, não permite transformar uma boa dissertação ou tese num manuscrito de qualidade idêntica ou superior. $O$ formato, espaço e narrativa de uma dissertação ou tese não são os mesmos utilizados em um artigo científico. Um dos aspectos mais apontados como negativos é a fluência do texto, que deixa de existir no manuscrito quando pedaços da tese ou dissertação são copiados e colados. Vale a pena procurar escrever um manuscrito, inclusive consultar como são os artigos publicados no periódico, e não fazer um "resumão". Isso pode aumentar a chance de aceitação. Mesmo assim, incentivo todos que têm resultados de pesquisa ou reflexões teóricas importantes sobre a Engenharia de Produção a submeter seus manuscritos para publicação na Gestão

\section{\& Produção.}

Neste número temos, de acordo com as áreas da Engenharia de Produção segundo a ABEPRO, três artigos em Gerência da Produção, mais três em Qualidade, outros três em Pesquisa Operacional, um em Estratégia e Organizações e outro em Sistemas de Informação. No primeiro artigo, Godinho Filho e Fernandes nos brindam com uma análise de uma revisão bibliográfica sobre manufatura enxuta, apontando possibilidades de trabalhos futuros no tema. Em seguida, Salerno faz uma análise da produção brasileira sobre organização do processo de trabalho, de forma a relacionar algumas obras, temas e o contexto econômico-político-social, propondo no final do texto algumas questões a serem pensadas por pesquisadores da área. Depois, Carnevalli, Miguel e Sassi apresentam dados relativos ao uso da abordagem Quality Function Deployment em empresas brasileiras, destacando as dificuldades encontradas e os benefícios obtidos pelas empresas pesquisadas. A seguir, Miranda e Almeida avaliam a aplicação dos métodos MAUT e ELECTRE II de decisão multicritério para apoiar a avaliação de programas de pós-graduação. Já Padilha e outros autores apresentam uma aplicação de planejamento de experimentos para determinação dos principais fatores críticos na implementação de sistemas ERP. Sellitto e Ribeiro propõem e aplicam, em empresas de transporte, um método para construção de indicadores de desempenho para os fatores intangíveis de empresas de prestação de serviços com base na estatística multivariada. Logo depois temos uma comparação entre dois modelos para o planejamento econômico de gráficos de controle de média e amplitude amostral feita por Turnes, Ho e Imaña. Em seguida, Barros e Moccellin propõem um algoritmo, denominado "Metaheurística Simulated Annealing de Busca do Gargalo Flutuante", para programação flow permutacional com tempos de setup assimétricos e dependentes da seqüência. Depois, Pádua e outros autores discutem o potencial das redes de Petri como forma de modelagem 
de processos de negócio. Galdamez e Carpinetti fazem uma aplicação de técnicas de planejamento e análise de experimentos num processo de moldagem por injeção plástica, de forma a melhorar a qualidade do processo. Por fim, Morabito e Silva apresentam uma abordagem para otimizar a programação de cargas de forno em fundições de mercado de pequeno porte, de forma a maximizar a produtividade e atender aos prazos de entrega e às restrições do processo.

Deste breve resumo daquilo que o leitor encontrará nesta edição da Gestão \& Produção, destacamos ainda a diversidade de trabalhos e de abordagens tanto de reflexão teórica quanto de aplicação e adaptação de métodos e técnicas. Isso é a Engenharia de Produção!

Boa leitura!

Prof. Dr. Roberto A. Martins

Editor da $G \& P$ 